\title{
Ocular adnexa carvenous hemagioma: case report
}

\begin{abstract}
Cavernous haemangioma is mostly intra-orbital and intraconal in location. A 40 year old male presented with painless progressive swelling of right upper eyelid of ten years duration. CT scan showed a soft tissue mass located on the right lateral aspect of the lacrimal gland bed. Excisional biopsy of the swelling was done. Histopathological findings confirmed cavernous haemangioma. We report the unusual finding of extraconal cavernous hemangioma anteriorly in the orbit lateral to the lacrimal gland bed.
\end{abstract}

\author{
Volume 7 Issue $6-2017$
}

\begin{abstract}
Aribaba OT,' Idowu OO, ${ }^{2}$ Olowoyeye AO,' Amusan $\mathrm{OO}^{\prime}$

'Department of Ophthalmology (Guinness Eye Centre), Lagos University Teaching Hospital/College of Medicine University of Lagos, Nigeria

${ }^{2}$ Department of Ophthalmology, University of California, USA
\end{abstract}

Correspondence: Aribaba OT, Department of Ophthalmology (Guinness Eye Centre), Lagos University Teaching Hospital, IdiAraba, Lagos, Nigeria, Email tade.aribaba@gmail.com

Received: November 01, 2017 | Published: December 04, 2017

\section{Introduction}

Cavernous haemangiomas are benign, slowly progressive vascular neoplasm of endothelial-lined spaces surrounded by a fibrous capsule. They are the most common vascular lesion of the orbits in adults accounting for $5-7 \%$ of all orbital tumours. ${ }^{1}$ According to the International Society for the Study of Vascular Anomalies (ISSVA) classification of vascular anomalies, these lesions are merely known as slow flow venous malformations. ${ }^{2}$ Thus, they are being referred to as harmatomas rather than tumours. They usually present in the middle age adults, 30-50 years of age and females are affected more than males. ${ }^{3}$ The ocular location is usually within the orbit and more often within the muscle cone, lateral to the optic nerve. Reports of unusual extraconal presentations are usually medial in location. ${ }^{1,46}$ Treatment is usually reserved for symptomatic patients (diplopia or visual disturbance) and includes surgical excision.

\section{Report of case}

A 40 year old man presented with a 10 year history of painless progressive swelling of the lateral two-thirds of the right upper eyelid. There was no history of proptosis, reduction in vision, ocular

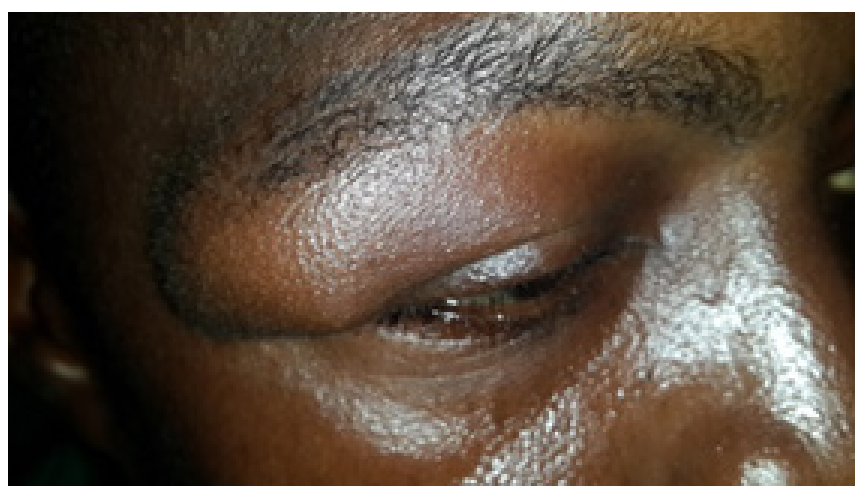

deviation or diplopia. There was no history of similar swelling in the past involving either eyelid or history of swelling in other parts of the body. Systemic review was not significant. On examination, the best corrected visual acuity was $6 / 6$ in both eyes. The main finding was a firm, non-tender, S-shaped mass on the lateral two-thirds of the right upper eyelid measuring $4 \times 4 \times 3 \mathrm{~cm}$. The swelling extended over the zygomatic bone; the overlying skin was normal as shown in Figure 1a\&b. Other ocular and systemic examination was essentially normal. Orbital CT scan revealed a soft tissue mass $(22 \times 15 \times 19 \mathrm{~mm})$ located on the right lateral aspect of the lacrimal gland bed. The mass showed punctate calcification. There was no evidence of erosion of the zygomatic bone or infiltration of the surrounding fat. The lateral rectus was normal. The left orbit was normal as demonstrated in Figure 2a\&b. Excisional biopsy was done through a lid crease incision and a purplish mass measuring $2.5 \times 1.5 \times 1 \mathrm{~cm}$ was found as depicted in Figure 3. Histopathological examination revealed an encapsulated mass with a homogenous dark cut surface on macroscopic examination. Microscopic examination of histologic sections showed a tumor composed of large dilated vascular channels filled with blood. The vascular channels are separated by connective tissue stroma. There was no atypia.

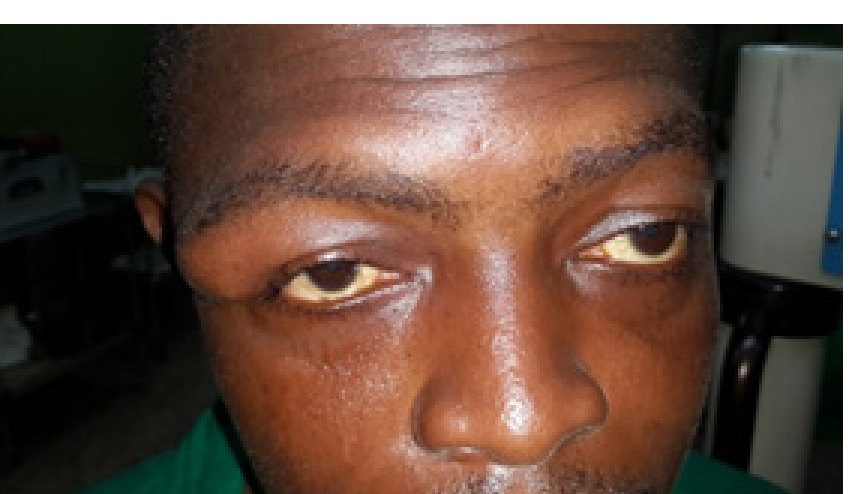

Figure la\&b The overlying skin was normal. 

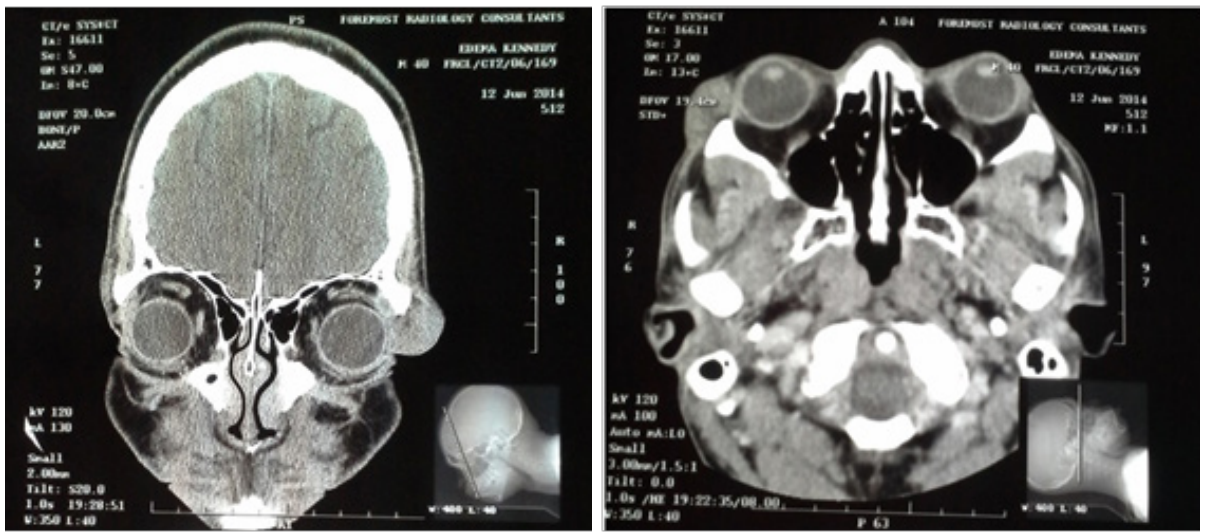

Figure 2a\&b The left orbit was normal.

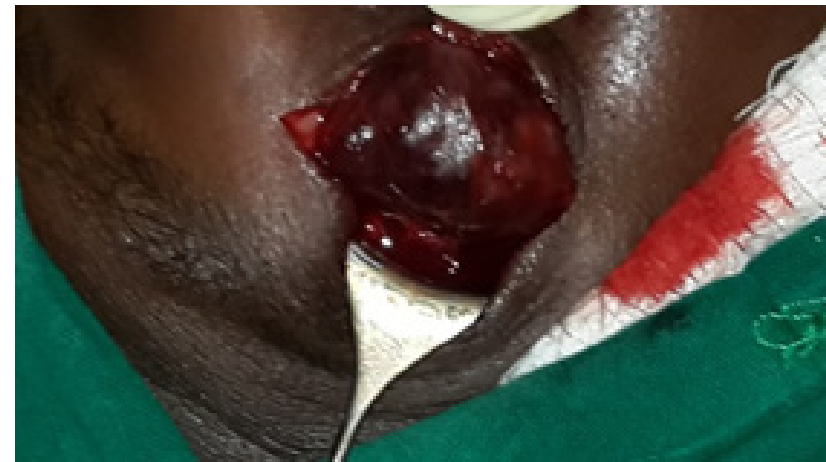

Figure 3 Excisional biopsy was done through a lid crease incision and a purplish mass measuring $2.5 \times 1.5 \times 1 \mathrm{~cm}$.

\section{Discussion}

Cavernous haemangiomas are the most common benign neoplasm of the orbit in adults. ${ }^{2}$ Women are affected more often than men. ${ }^{2}$ The most frequent locations are the retrobulbar muscle cone, especially the lateral aspect of the intraconal space. ${ }^{3}$ It is classified as a congenital low-flow vascular malformation. ${ }^{1}$ A painless, gradually progressive proptosis and visual disturbance are the main clinical signs of Cavernous haemangiomas. ${ }^{7}$ Ninety-three percent of the patients can be accurately diagnosed preoperatively based on echography and CT/MRI imaging. ${ }^{7}$ CT shows homogeneous soft tissue density, and may show small calcifications or phleboliths. ${ }^{8}$ Histologically, the lesions are encapsulated and are composed of large cavernous spaces containing red blood cells. Complete removal of the tumor is possible as the Cavernous haemangioma is totally encapsulated and meticulous surgical dissection can give good cosmetic result to the patient. ${ }^{1}$ This is unlike paediatric ocular hemangiomas which are usually capillary haemangioma, are unencapsulated, diffuse and difficult to excise. ${ }^{10}$

While the tumor is typically described as intraconal, there have been reports of extraconal cavernous hemangioma. ${ }^{1,4,5,6}$ Reports of unusual extraconal presentations are usually medial in location ${ }^{1,4,5}$ including a preseptal presentation at the superior nasal orbital angle. ${ }^{6}$ We report the unusual finding of extraconal cavernous hemangioma anteriorly in the orbit lateral to the lacrimal gland bed. This unusual presentation of cavernous hemangioma as a mass in the lateral two-thirds of the lid with no associated proptosis, ocular deviation or visual impairment adds to the differentials of supero-laterally located lid masses. The most frequently calcified extraocular masses are vascular lesions (hemangioma, lymphangioma, and varix). ${ }^{9}$ Therefore cavernous hemangiomas should be considered with findings of calcifications on imaging in superolateral orbital lesions and lid masses.

\section{Acknowledgments}

None.

\section{Conflicts of interest}

Author declares that there are no conflicts of interest.

\section{Funding}

None.

\section{References}

1. Holds J, Chang W, Durairaj V, et al. Cavernous Hemangioma. In: Cantor LB, Rapuano CJ, Cloffi GA, editors. Basic and Clinical Science Course (BCSC) section 7: Orbit, Eyelids and Lacrimal System. USA: American Academy of Ophthalmology (AAO), San Francisco (CA). 2014; p. 64-65.

2. Rizvi S, Yousuf S, Maheshwari V, et al. Multiple cavernous haemangiomas of the the orbit and conjunctiva: A rare association. J Surg case reports. 2012;2012(8):8.

3. Ansari SA, Mafee MF. Orbital cavernous hemangioma: role of imaging Neuroimag Clin North Am. 2005;15(1):137-158.

4. Yan J, Li Y. Unusual presentation of an orbital cavernous hemangioma. $J$ Craniofac Surg. 2014;25(4):e348-e349.

5. Anand R, Deria K, Sharma P, et al. Extraconal cavernous hemangioma of orbit: A case report. Indian J Radiol Imaging. 2008;18(4):310-312.

6. D'hermies F, Cherif N, Hurbli T, et al. Unusual preseptal location of an orbital cavernous hemangioma in African patient. J Fr d'ophtalmologie. 2000;23(6):631-634.

7. Yan J, Wu Z. Cavernous hemangioma of the orbit: analysis of 214 cases Orbit. 2004;23(1):33-40.

8. Khan SN, Sepahdari AR. Orbital masses: CT and MRI of common vascular lesions, benign tumors, and malignancies. Saudi J Ophthalmol Off J Saudi Ophthalmol Soc. 2012;26(4):373-383.

9. Froula PD, Bartley GB, Garrity JA, et al. The differential diagnosis of orbital calcification as detected on computed tomographic scans. Mayo Clin Proc. 1993;68(3):256-261.

10. Darrow DH, Greene AK, Mancini AJ, et al. Diagnosis and management of infantile hemangioma. Pediatrics. 2015;136(4):e1060-e1104. 